\title{
Breakthrough Strategy of Enterprise Financial Management in the Era of Network Economy
}

\author{
Jiangfan Ma \\ Macau University of Science and Technology, Macau, China
}

Keywords: Network Economy; Enterprise; Financial Management

\begin{abstract}
With the advent of the information age, Internet technology has developed rapidly. At the same time, due to the deepening of global economic integration, the market competition environment in which Chinese enterprises are located has become increasingly complicated. Under such circumstances, the old corporate financial management methods have gradually become obsolete and cannot meet the requirements of enterprise progress and external supervision. Based on this, the paper puts forward the expected goals of transformation construction by analyzing the various financial functions that existed before the financial transformation of enterprises. According to the principle of informatization construction, build the technical foundation of financial transformation. Finally, through the three aspects of financial management information construction, financial sharing center construction and financial outsourcing model construction, the financial management transformation of enterprises in the era of network economy is realized.
\end{abstract}

\section{Introduction}

With the advent of the information age, Internet technology has developed rapidly. At the same time, due to the deepening of global economic integration, the market competition environment in which Chinese enterprises are located has become increasingly complicated. In this context, the old financial management methods of the past are difficult to keep up with the development of the times, and can not meet the requirements of enterprise progress and external supervision. Financial management covers all processes of supply, production and sales in the business activities of the company. Its level of good and bad is directly related to the income of the enterprise and affects the development of the enterprise in the long run. In view of this, in order to make the financial management of enterprises easier and faster, and to achieve the purpose of reducing financial management costs and improving financial management efficiency, enterprises should fully utilize the characteristics held by the "Internet +" era to promote the optimization of corporate financial management methods. Transformation, and ultimately achieve effective integration of Internet technology and financial management. However, due to the current imperfect system in China, the backward construction of information technology and the shortage of relevant professionals, it has hindered the transformation of corporate financial management under the background of "Internet + accounting". Based on this, the article takes this as an entry point and conducts in-depth research to promote the improvement of the financial management level of Chinese enterprises [1].

\section{The Shortcomings of Corporate Financial Management under the Network Economy}

\subsection{The Information Island Phenomenon Is Serious.}

The information island phenomenon means that the enterprise lacks the necessary Internet technology support in the production management and management environment, which in turn causes the enterprise function module to fall into a situation full of randomness. In actual operation, because the informationization process of the enterprise progresses relatively fast, the information demand for related services cannot be controlled well. After the information needs are publicized, because there is no comprehensive plan or the original information is gradually solidified, and it is developed separately, that is, the overall structure of the information system is that it does not 
incorporate subsequent requirements into the existing system processes of the enterprise, but in an accumulation. Therefore, many information systems in the enterprise are incompatible with each other, forming a distribution pattern of information systems similar to an island. Many companies have difficulty in communicating financial data between their headquarters and their subsidiaries and departments when there is no financial transformation. According to the requirements of warehouse management information, in the storage, it is necessary to export the inventory information to the storage system and financial accountants to organize the information. The manual modification of the financial system is not only time consuming, but also reduces the accuracy and timeliness of the data. In addition, in different business systems, the data collection results can not correctly reflect the real problems [2].

\subsection{Inefficient Management of Funds and Use.}

Capital is the most profitable production factor in the market competition. Therefore, enterprises should establish a management concept around capital development, aiming at the effective use of funds and promoting the improvement of enterprise efficiency. In the transition before financial information, because there is no standard system, many enterprises cannot make pre-estimation and overall planning for the fund scheduling and use of subsidiaries. The subsidiary company's fund management is loose and inefficient, which increases the capital operation and risk of the company. For example, some of the companies have no good use of funds in the case of excess funds, and some because of the lack of funds to operate the project, through which the company can not really grasp the actual corporate capital turnover and other information, not only increase the company's The pressure on total capital operation also makes it impossible to coordinate the use of funds, which poses a big problem for the allocation and development of corporate resources [3].

\subsection{Failure to Meet the Financial Information Requirements of All Parties.}

In the context of the deepening of global economic integration, the business environment in which enterprises are located is complex and multifaceted. Because the financial information is always a slap in the face, and the existing business system has the phenomenon of information islands, the existence of this situation makes the financial information obtained by the enterprise not timely or accurate, and the slowness of the information analysis results cannot reach the change of the environment in which the enterprise is located. Requirements, it is difficult to help business managers make the right decisions.

The rapid development of the connotation and extension of corporate financial management has brought about new modules such as enterprise management and mergers and acquisitions, as well as risk management and control. The past financial management methods cannot promote the progress of financial integration due to the organization of accounting and management control, and may causes companies to lose their strengths and opportunities.

\section{The Transformation Strategy of Enterprise Financial Management under the Network Economy}

\subsection{Financial Management Informationization Construction.}

In order to promote the integration of finance and enterprises in the construction of information technology, it is necessary to remove the previous financial awareness and commercial barriers. Informatization construction adheres to the principle of "focusing on finance and focusing on business". The efficient operation and development of information systems meets the concerns of the business and abstracts the complexity of the business to meet the changing business model. By using the value stream to link the various processes of the business, the company's financial management system is integrated into the risk management and control of the enterprise, and the accounting and business are integrated to achieve the purpose of automated production of business-driven accounting information. It meets both flexible business requirements and financial standards [4]. 
In order to avoid the information island phenomenon, the current business module should be fully integrated, and efforts should be made to promote the sharing of financial information. In order to achieve a unified goal, we should use integration as a means to refine the essence of the business through business performance and standardize the expression of business differences. Moreover, we believe that the existing system also includes: establishing a central system, transforming integrated modules, abandoning some low-applicability modules, and transforming problem modules.

Divide the design and development implementation into two phases, reduce the cost of information construction, and find a good support for the enterprise. In the design stage, according to the statistical results, the business practice of the business is understood, the business essence is used to design the target, the requirements specification, the explicit expression process and the data and the interface are compiled. Designed to review business units, they can clearly express and solidify business elements, and then implement development in accordance with standardized development code. The new system is more suitable for the needs of the enterprise, but also promotes the progress of the business.

\subsection{Construction of Financial Sharing Center.}

The financial sharing center is built to improve the efficiency of corporate capital operations. From the relevant theory of financial sharing center and its operating experience, the key to sharing is to efficiently and centrally deal with the large number of invalid financial exchanges in the total system by means of informationization and specialization. Because there is a financial sharing center in the total system, helping the financial exchange of system business modules to support services across organizations and regions can not only improve accounting efficiency, but also help control the financial risks of enterprises, so enterprises should start in subordinate units.

The financial sharing center is equivalent to a basic financial information processing unit, which should be closely related to the business module of the enterprise. With the accurate feedback of the business reality, the information can be quickly transmitted to the enterprise manager. The Financial Sharing Center standardizes the financial management of business modules, which not only speeds up the processing of business, but also reduces the error rate of transactions with the standardized design of information systems.

\subsection{Construction of Financial Outsourcing Model.}

Financial outsourcing is a more advanced financial concept, and it is also a gradual exploration process for enterprises. It requires the accumulation of time experience. Therefore, in accordance with the principle of phased implementation, experimentation, and stabilization and improvement, enterprises must implement financial outsourcing experiments in sales companies and then promote them after maturity. The implementation of financial outsourcing should improve the quality and efficiency of accounting, and facilitate the financial transformation of stock companies and the entire group of companies, thereby promoting and ensuring the realization of the company's strategic goals. The financial outsourcing company has the status of an independent legal entity and has the same legal status as the entrusted business unit. It is not a functional department, but a business unit. It uses the service agreement as the benchmark for business operations and is generally divided and managed according to the business cycle.

Accounting outsourcing requires a complete set of financial accounting processes, including order processing, fund settlement, accounts receivable settlement, accounts payable settlement, tax agency reconciliation, invoice management, reimbursement and document management and accounting services.

In the service agreement, the content of the service, the time and quality of the service are clarified, and the confidentiality clause is strengthened in the agreement, which stipulates the liability for breach of contract. Therefore, on the basis of improving the content of the service agreement, strengthening the implementation of the service agreement will be the legal basis for ensuring financial outsourcing and financial transformation. In order to ensure the service quality and service level of the financial sharing center, enterprises providing outsourcing services need to 
establish a quality control center, strengthen audit management and process control, establish two audit systems, ensure service quality, reduce errors, and prevent fraud. In order to ensure the information quality of financial outsourcing enterprises, ensure the timely reflection of security and financial information, the third-level auditors of the outsourcing service providers of the finance department, responsible for all matters within the scope of the final payment service and business support. In addition, Headquarters Finance will form an internal audit team responsible for substantive review of the financial statements, books and credentials provided by outsourced service providers to ensure the authenticity and integrity of the business and the standardization of the basic work.

\section{Conclusion}

Under the network economy, enterprise financial management has serious information island phenomenon, low capital control and inefficient use, and cannot meet the financial information requirements of all parties. Therefore, it is necessary to promote the optimization and transformation of the financial management mode of enterprises by fully utilizing the characteristics held by the "Internet +" era, and finally realize the effective integration of Internet technology and financial management.

\section{References}

[1] Wang Chunping. Discussion on the Cultivation of Financial Management Professionals in Higher Vocational Colleges under the New Internet Economy [J]. Times Economics and Trade, 2018(23): 98-99.

[2] Chen Yingbo. Research on the Transformation and Upgrading of Financial Management of Small and Medium-sized Enterprises_-Based on the Perspective of Internet [J].SME Management and Technology, 2018(08):49-50.

[3] Li Yunyu. Research on Enterprise Financial Data Transformation Strategy from the Perspective of Internet + Management Accounting [J]. Finance and Accounting, 2018(22):100.

[4] Pang Shiyu. On the transformation and development of financial management of commercial banks under the new situation [J]. Modern Economic Information, 2018 (15): 211. 